\title{
Quantification of Cyclobenzaprine in Human Plasma by LC/MS/MS and its Pharmacokinetics Application
}

\author{
Mohamed Raslan ${ }^{1,2}$, Sara AR ${ }^{1}$, Eslam MS ${ }^{1}$ and Nagwa A Sabri ${ }^{2 *}$ \\ ${ }^{1}$ Drug Research Centre, Cairo, Egypt \\ ${ }^{2}$ Department of Clinical Pharmacy, Faculty of Pharmacy, Ain Shams University, \\ Cairo, Egypt \\ *Corresponding Author: Nagwa A Sabri, Department of Clinical Pharmacy, Faculty \\ of Pharmacy, Ain Shams University, Cairo, Egypt.
}

Received: October 08, 2020

Published: October 30, 2020

(C) All rights are reserved by Nagwa A Sabri., et al.

\begin{abstract}
Background: Cyclobenzaprine is a skeletal muscle relaxant used in management of focal muscular disturbances and as an adjunct to physical therapy for relief of muscle spasm.

Aim: Establishment of a bio-analytical method in order to quantify cyclobenzaprine in plasma and investigate cyclobenzaprine pharmacokinetics in human plasma and its application in clinical studies including comparative bioavailability studies.

Methods: After extraction of cyclobenzaprine from plasma, analysis was performed with mobile phase ratio of acetonitrile: $0.1 \%$ formic acid $90: 10$ at a flow rate of $0.5 \mathrm{ml} / \mathrm{min}$, ESI positive mode, and $\mathrm{m} / \mathrm{z} 276.6 \rightarrow 216.4$ for cyclobenzaprine, and $325.1 \rightarrow 109$ for escitalopram (IS). The bioequivalence study was involving 24 volunteers in a crossover pattern. Pharmacokinetic parameters AUC $_{0-t^{\prime}}$ $\mathrm{AUC}_{0 \text {-inf, }} \mathrm{C}_{\max }$ and $\mathrm{T}_{\max }$ used for assessment of bioequivalence of the generic and reference products.

Results: The developed bioanalytical method showed that the average recovery of cyclobenzaprine from plasma was $82.883 \%$, LLOQ $0.05 \mathrm{ng} / \mathrm{ml}$. Correlation coefficient $\left(\mathrm{r}^{2}\right)$ 0.9998. Analysis of variance showed that there was no significant difference between generic and reference products.

Conclusion: The established LC/MS/MS method is fully validated for the determination of cyclobenzaprine in biological samples and is suitable for clinical pharmacokinetic studies, clinical trials and monitoring drug levels in plasma to ensure clinical efficacy and safety, avoid therapeutic failure or incidence of adverse events. Moreover, generic product was found to provide the same rate and extent of drug absorption as the reference product.
\end{abstract}

Keywords: Cyclobenzaprine; LC/MS/MS; Muscle Spasm; Sustained Release Capsule; Therapeutic Drug Monitoring

\section{Introduction}

Cyclobenzaprine is a medication used to relieve skeletal muscle spasms and is related to tricyclic antidepressants and acts via central nervous system. Its action is mainly by affecting the distal part of the brain to decrease activity of somatic nervous system which influence alpha motor neurons and gamma motor neurons [1]. Cyclobenzaprine possess an antispasmodic benefit in management of focal muscular disturbances [2,3].
Cyclobenzaprine is marketed in the form of Sustained release capsules, as a cyclobenzaprine hydrochloride $15 \mathrm{mg}$ and $30 \mathrm{mg}$, under brand name Amrix ${ }^{\circledR} 15 \mathrm{mg}$ and $30 \mathrm{mg}$ sustained release capsules [4]. Cyclobenzaprine can be used as an adjuvant therapy beside rest and physiotherapy for relaxing muscle spasm related to acute painful conditions like low back pain, neck pain, and fibromyalgia [5-7]. 
The recommended daily dose of cyclobenzaprine for adults is $15 \mathrm{mg}$. Some patients may need a daily dose of $30 \mathrm{mg}$ which can be taken as one $30 \mathrm{mg}$ capsule or as two $15 \mathrm{mg}$ capsules. It is not recommended to administer cyclobenzaprine for more than 2 to 3 weeks [7].

After single dose administration of cyclobenzaprine 30mg sustained release capsules, mean cyclobenzaprine $\mathrm{C}_{\text {max }}, \mathrm{AUC}_{\mathrm{o} \text {-inf }}, \mathrm{T}_{1 / 2}$ was $19.9 \pm 5.9 \mathrm{ng} / \mathrm{ml}, 779.9 \pm 277.6 \mathrm{ng} . \mathrm{hr} / \mathrm{ml}, 32.0 \pm 10.1$ hour respectively and mean $\mathrm{T}_{\max }$ was equal to $7.1 \pm 1.6$ hour [8]. In a pharmacokinetics study of cyclobenzaprine $30 \mathrm{mg}$ sustained release capsules the reported mean values of $\mathrm{C}_{\max }, \mathrm{AUC}_{\mathrm{o} \text {-inf }}, \mathrm{T}_{1 / 2}$, and $\mathrm{T}_{\max }$ were $19.2 \pm 5.1 \mathrm{ng} / \mathrm{ml}, 1055.2 \pm 301.9 \mathrm{ng} . \mathrm{hr} / \mathrm{ml}, 49.0 \pm 8.3 \mathrm{hr}$ and 8 hrs respectively [9].

Different published bio-analytical methodologies are developed for the estimation of cyclobenzaprine in different dosage forms and human plasma. The developed methods include, thin-layer chromatography [10], packed column or capillary gas chromatography (GC) [11,12], HPLC with UV detection [13], LC/MS/MS with APCI [14] and ESI source $[15,16]$.

An analytical method used for determination of cyclobenzaprine in biological samples using HPLC-UV method and sample extraction with liquid extraction procedure using methylene chloride: pentane 30:70 (v/v), shows a lower quantitation limit LLOQ of $1 \mathrm{ng} / \mathrm{ml}$ [17]. A sensitive analytical method used for determination of cyclobenzaprine in biological samples using LC/MS/MS method, and sample extraction procedure with methyl tertbutyl ether shows a lower quantitation limits LLOQ of $0.25 \mathrm{ng} / \mathrm{ml}$ [18]. A reported bioanalytical assay using a liquid-liquid extraction from basified biological sample and detection once with LC/MS/MS, or HPLC-UV shows a lower quantitation limits LLOQ of $0.1 \mathrm{ng} / \mathrm{ml}$ and $0.5 \mathrm{ng} / \mathrm{ml}$ respectively [19].

Cyclobenzaprine determination in biological samples using LC/ MS/MS which after extraction from human plasma with organic solvent, the compound was chromatographed on a reversed phase agela C18 column with an eluting solvent of acetonitrile: $5 \mathrm{mM}$ ammonium acetate: formic acid (90:10:0.01, v/v/v). Mass parameters were set on multiple reaction monitoring (MRM) and positive ESI using the respective mass to charge ratios, $\mathrm{m} / \mathrm{z} 276.2 \rightarrow 216.1$ for cyclobenzaprine and $\mathrm{m} / \mathrm{z} 325.1 \rightarrow 109.0$ for escitalopram, with LLOQ of $0.02 \mathrm{ng} / \mathrm{ml}$ and a linear dynamic range of $0.02 \mathrm{ng} / \mathrm{ml}$ to $10 \mathrm{ng} / \mathrm{ml}[20]$.
For a wider linear dynamic range, a sensitive LC/MS/MS assay developed in which drug extracted by liquid-liquid extraction from human plasma and a chromatographic separations were achieved on Ultimate XB-CN column using mobile phase of acetonitrile-water $(40: 60, v / v)$ containing $10 \mathrm{mM}$ ammonium acetate and $0.1 \%$ formic acid. The method showed to be valid. The MRM was based on $\mathrm{m} / \mathrm{z} 276.2 \rightarrow 216.2$ for cyclobenzaprine, $\mathrm{m} / \mathrm{z} 325.2 \rightarrow 109.1$ for escitalopram. The lower limit of quantitation LLOQ was $0.049 \mathrm{ng} /$ $\mathrm{ml}$ and showed to be linearity from 0.049 to $29.81 \mathrm{ng} / \mathrm{ml}$ [21].

This study was conducted to examine the efficiency of the developed bioanalytical method for quantitation of cyclobenzaprine in biological fluids through a valid bioanalytical method suitable for its application in comparative bioavailability and pharmacokinetics studies and monitoring its levels in patients to confirm reaching the desired therapeutic goals with minimal side effects.

A conducted comparative bioavailability between cyclobenzaprine $30 \mathrm{mg}$ sustained release capsule generic product and reference product proved that the method is accurate, precise, selective and fully validated. The study was conducted on 24 healthy subjects as per protocol. The subjects received one sustained release capsule of generic product and one sustained release capsule of reference product, in an open label randomized crossover design, separated by two - weeks washout period between treatments [22]. Analysis of plasma would be done through developing and validating an LC/ MS/MS method in compliance with the international guidelines [23]. WinNonlin program was utilized for pharmacokinetics calculations and SAS software was involved in statistical analysis. The $90 \%$ C.I. for $\mathrm{AUC}_{0-\mathrm{t}}, \mathrm{AUC}_{0 \text {-inf }}$ and $\mathrm{C}_{\max }$ were calculated for the ratio between treatments and results showed to be in the limit of $80 \%$ to $125 \%$ confidence limits [24].

\section{Materials}

\section{Chemicals}

LC/MS/MS grade Water, methanol (SIGMA Aldrich, Germany), acetonitrile (Scharlab, Spain), formic acid (Scharlab, Spain), sodium tertaborate (Scharlab, Spain), diethylether (Fisher Scientific, UK) and dichloromethane (Fisher Scientific, UK).

\section{Equipment}

Micropipettes (P200, and P1000), pipettes tips yellow (range from 5 to $200 \mu \mathrm{L}$ ) and blue (range from 200 to $1000 \mu \mathrm{L}$ ), disposable centrifuge glass test tubes, vortex, vacuum pump, and PH-meters (Boeco, Germany), water purifier (ELGA, U.K.), sonicator (Crest, 
U.S.A.), analytical balance (Sartorius, U.S.A.), concentrator plus/vacufuge ${ }^{\circledR}$ plus (Eppendorf, Germany) and LC-MS/MS Agilent 6410B Triple Quad, USA.

\section{Methods}

The bioanalytical method parameters

\section{Chromatography}

An in house bioanalytical method was developed using mobile phase of methanol: $10 \mathrm{mM}$ ammonium acetate: acetonitrile $(4: 16: 80) \mathrm{v} / \mathrm{v} / \mathrm{v}$, flow rate of $0.63 \mathrm{ml} / \mathrm{min}$ and $2 \mathrm{ul}$ was injected. The mass detector was operated at electrospray ionization positive mode, $\mathrm{m} / \mathrm{z}$ was $454 \rightarrow 285$ for cyclobenzaprine and $396.1 \rightarrow 277.2$ for escitalopram.

The fragment or energy was set at 130 and 100, while collision energy was set at 20 and 5 for cyclobenzaprine and escitalopram respectively.

\section{Preparation of solutions}

\section{Master standard solution}

Accurately weighed $11.32 \mathrm{mg}$ of standard cyclobenzaprine $\mathrm{HCl}$ (equivalent to $10 \mathrm{mg}$ cyclobenzaprine) were transferred to $100 \mathrm{ml}$ volumetric flask, about $80 \mathrm{ml}$ methanol was added, sonication was done for 10 minutes and the volume was completed with methanol in order to obtain a final solution of $100 \mathrm{ug} / \mathrm{ml}$ cyclobenzaprine "Solution A". From solution (A) $0.5 \mathrm{ml}$ was transferred to $100 \mathrm{ml}$ volumetric flask and volume was completed with methanol to obtain final concentration of $500 \mathrm{ng} / \mathrm{ml}$ cyclobenzaprine "Solution B".

Working solutions

\begin{tabular}{|l|c|c|c|}
\hline $\begin{array}{l}\text { Solution } \\
\text { used }\end{array}$ & $\begin{array}{c}\text { Volume } \\
\text { taken }\end{array}$ & $\begin{array}{c}\text { Concentration } \\
\text { (ng/ml) }\end{array}$ & $\begin{array}{c}\text { Final volume } \\
\text { (ml) }\end{array}$ \\
\hline \multirow{4}{*}{ “Solution B" } & $10 \mathrm{ul}$ & 0.5 & 10 \\
\cline { 2 - 4 } & $20 \mathrm{ul}$ & 1 & 10 \\
\cline { 2 - 4 } & $100 \mathrm{ul}$ & 5 & 10 \\
\cline { 2 - 4 } & $200 \mathrm{ul}$ & 10 & 10 \\
\cline { 2 - 4 } & $500 \mathrm{ul}$ & 25 & 10 \\
\cline { 2 - 4 } & $1 \mathrm{ml}$ & 50 & 10 \\
\cline { 2 - 4 } & $2 \mathrm{ml}$ & 100 & 10 \\
\cline { 2 - 4 } & $5 \mathrm{ml}$ & 250 & 10 \\
\cline { 2 - 4 } & $10 \mathrm{ml}$ & 500 & 10 \\
\hline
\end{tabular}

All dilutions were done with methanol.

\section{Preparation of escitalopram standard solution}

Accurately $10 \mathrm{mg}$ of standard escitalopram were transferred to a $100 \mathrm{ml}$ volumetric flask and $80 \mathrm{ml}$ of methyl alcohol was added followed by sonication for 10 minutes, then volume was completed with methyl alcohol to obtain a solution of $100 \mathrm{ug} / \mathrm{ml}$ escitalopram solution (A). $0.1 \mathrm{ml}$ of it was transferred to a $100 \mathrm{ml}$ volumetric flask and completed to volume with methyl alcohol to obtain final concentration of $100 \mathrm{ng} / \mathrm{ml}$ escitalopram solution (B).

Serial dilutions of standard cyclobenzaprine in human plasma

Prepared by transferring $50 \mathrm{ul}$ of the prepared working solutions of cyclobenzaprine at concentrations range from 0.5 to 500 $\mathrm{ng} / \mathrm{ml}$ to a centrifuge tubes containing $500 \mathrm{ul}$ of blank plasma.

\section{Sample preparation}

A $500 \mathrm{ul}$ of human plasma samples were added in a centrifuge test tubes and $50 \mathrm{ul}$ of escitalopram working solution $100 \mathrm{ng} / \mathrm{ml}$ was added, and vortex-mix of samples was done for approximately 30 seconds, $50 \mathrm{ul}$ of $0.025 \mathrm{M}$ sodium borate $\mathrm{pH} 9$ was added and vortex was done for 1 minute, then $2 \mathrm{ml}$ of diethyl ether: methylene chloride 70:30 was added and vortex was done for 1 to 2 minutes, followed by centrifugation at $3500 \mathrm{rpm}$ for 5 minutes and the clear supernatant layer was evaporated to dryness, where, the obtained dry residue was reconstituted with 200 ul mobile phase and injected on LC/MS/MS.

\section{Quantitation}

Drug concentrations of withdrawn plasma samples were calculated through application of: $\mathrm{Y}=\mathrm{aX}+\mathrm{b}$, where; $\mathrm{Y}$ : response ratio, $\mathrm{X}$ : unknown concentration of drug in plasma samples, a: calibration curve slope, b: Y-Intercept.

Bioequivalence study

Study ethics

This study was conducted in accordance with the ICH and GCP guidelines adopted by the European agency for the evaluation of medicinal products (EMEA) and after ethics committee approval on the bioequivalence study protocol of cyclobenzaprine $30 \mathrm{mg}$ extended release capsule (Study Code: REL-CHPI-BES-0215/0207). Essential documents and records were all archived according to drug research center (DRC) internal procedures for authorized direct access. 
Written informed consents were signed by the participant and clinical investigator and all study aspects where discussed with the participants before starting of screening without any obligations to continue the study if they didn't want to.

Clinical Investigator, study director (principal investigator), licensed physicians responsible for physical examination and following-up of the subjects for appearance of any side or adverse effects, measurement of vital signs throughout the study including blood pressure, pulse rate, body temperature, respiratory rate before and all over the study and registered nurses were responsible for blood sampling.

\section{Inclusion criteria}

Age between 18 to 55 years, the calculated body mass index should lie within normal acceptable limits, no history of contribution in any pharmacokinetics study, and normal physiological examination, laboratory data within normal limits. Subjects should not be alcoholic or drug abusers and shouldn't have any known history for both. It is preferred to select non-smoker subjects, and if subjects are smokers, they should not smoke more than 8 cigarettes per day.

\section{Exclusion criteria}

A known drug hypersensitivity, GIT problems, auto-immune diseases, kidney diseases or kidney dysfunction, CVS diseases, diabetics, hepatic disease, hematological abnormalities, respiratory diseases, alcohol intake or drug abuse history, positive HIV-I, smoking and if including they should be identified, abnormal laboratory values, subject administered any medication less than two weeks of the study starting date, subjects who have donated blood or who participated in clinical studies that requires more than $500 \mathrm{ml}$ of blood to be withdrawn within month and half preceding study starting date.

\section{Subjects}

Twenty-four healthy adult volunteers participated in the comparative bioavailability study after being subjected to complete medical and laboratory assessment and insuring that they are in compliance with the required inclusion/exclusion criteria. Concurrent medications were not allowed during the study time course. No food intake was allowed for four hours after study dose administration. At 11:30 they received a standard meal and at 15:30 a second standardized meal was introduced.

\section{Study design}

A randomized two-way crossover design comparing the bioavailability of generic versus reference cyclobenzaprine $30 \mathrm{mg}$ sustained release capsules in 24 healthy adult volunteers under fasting state with a washout period of two weeks. The number of required blood samples and their disposition after collection and the wash out period were designed according to cyclobenzaprine pharmacokinetics.

\section{Sample collection}

Collected number of blood samples were $17 \mathrm{X} 5 \mathrm{ml}$ in each study period at the following time intervals; 0 (directly prior to dosing), 1 hour, 2, 3, 4, 5, 6, 7, 7.5, 8, 9, 10, 11, 12, 24, 48 and 72 hours after dosing, where, the total amount of blood withdrawn during the two periods did not exceed $170 \mathrm{ml}$.

Blood sample collection was performed into a tubes containing anticoagulant EDTA disodium and centrifuged at approximately 4000 r.p.m. for 10 minutes, supernatant was separated and stored at $-80{ }^{\circ} \mathrm{C}$ until analysis.

\section{Analysis of plasma samples}

The withdrawn volunteers' samples were analyzed by using LCMS/MS technique for the quantitation of cyclobenzaprine in human plasma.

\section{Pharmacokinetic calculations}

The pharmacokinetic parameters of cyclobenzaprine assessed were $\mathrm{C}_{\max }, \mathrm{t}_{\text {max }}, \mathrm{t}_{1 / 2 \mathrm{e}}, \mathrm{K}_{\mathrm{e}}$, and $\mathrm{AUC}_{0-72}$.

\section{Statistical analysis}

Analysis of variance (ANOVA) calculated using SAS software. Bioequivalence of both drug products could be fulfilled if statistical analysis results of $\mathrm{AUC}_{0-72}$ and $\mathrm{C}_{\max }$ fall within $90 \%$ confidence limit of $80 \%$ to $125 \%$.

\section{Results}

Analytical procedure validation

Chromatograms of cyclobenzaprine

Cyclobenzaprine and escitalopram were well separated with retention time of $0.8 \mathrm{~min}$., chromatographic peaks were in accordance with guidelines requirements and thus facilitated measurement of peak responses. 


\section{Method validation}

Peak response ratios of different amounts of cyclobenzaprine in plasma in the range of 0.05 to $50 \mathrm{ng} / \mathrm{ml}$ was highly linear as correlation coefficient $\left(\mathrm{r}^{2}\right)$ was found to be 0.9998 and the average results of interday variation C.V.\% was $1.789 \%$ in compliance with FDA Guidelines [23]. Accuracy and precision was assessed at three different concentrations in the range of predicted drug concentrations on within and between-day basis. Intra-day and inter-day accuracy results showed an average recovery percentage of $97.641 \%$ and $99.028 \%$ with an average C.V. $\%$ of $1.789 \%$. The average stability percentage of cyclobenzaprine was greater than $95 \%$ confirming cyclobenzaprine stability in the studied conditions.

Application of the developed bioanalytical method in comparative bioavailability study

\section{Clinical observation}

The drug was well tolerated by all participating subjects, blood sampling was obtained during the two period as completely at the proper time, and no adverse events was observed during the study time course.

\section{Comparative bioavailability study}

The mean maximum plasma concentration $\left(\mathrm{C}_{\max }\right)$ was found to be $18.799 \pm 2.639 \mathrm{ng} / \mathrm{ml}$ and $19.814 \pm 2.235 \mathrm{ng} / \mathrm{ml}$, time point of maximum plasma concentration $\left(\mathrm{t}_{\max }\right) 7.250 \pm 0.659 \mathrm{hr}$ and 7.292 $\pm 0.327 \mathrm{hr}$, half-life of drug elimination $\left(\mathrm{t}_{1 / 2 \mathrm{e}}\right) 30.830 \pm 9.681 \mathrm{hr}$ and $31.319 \pm 9.735 \mathrm{hr}$, Area under curve from zero to $72 \mathrm{hrs}\left(\mathrm{AUC}_{0-72}\right)$ $337.146 \pm 86.487 \mathrm{ng} . \mathrm{hr} / \mathrm{ml}$ and $325.328 \pm 67.018 \mathrm{ng} . \mathrm{hr} / \mathrm{ml}$ for the generic and reference products respectively.

\begin{tabular}{|l|c|c|}
\hline \multirow{2}{*}{$\begin{array}{l}\text { Pharmacokinetic } \\
\text { Parameter }\end{array}$} & \multicolumn{2}{|c|}{ Mean \pm SD } \\
\cline { 2 - 3 } & Generic product & Reference product \\
\hline $\mathrm{C}_{\max }(\mathrm{ng} / \mathrm{ml})$ & $18.799 \pm 2.639$ & $19.814 \pm 2.235$ \\
\hline $\mathrm{T}_{\max }(\mathrm{hr})$ & $7.250 \pm 0.659$ & $7.292 \pm 0.327$ \\
\hline $\mathrm{AUC}_{0-72}(\mathrm{ng} . \mathrm{hr} / \mathrm{ml})$ & $337.146 \pm 86.487$ & $325.328 \pm 67.018$ \\
\hline $\mathrm{K}_{\mathrm{e}}\left(\mathrm{hr}^{-1}\right)$ & $0.025 \pm 0.007$ & $0.024 \pm 0.008$ \\
\hline $\mathrm{t}_{(1 / 2) \mathrm{e}}(\mathrm{hr})$ & $30.830 \pm 9.681$ & $31.319 \pm 9.735$ \\
\hline
\end{tabular}

Table 1: Pharmacokinetics of generic and reference cyclobenzaprine products.

\begin{tabular}{|c|c|c|c|}
\hline \multirow{2}{*}{$\begin{array}{c}\text { Pharmacokinetic } \\
\text { Parameter }\end{array}$} & Point estimate & $\begin{array}{c}\text { Lower } \\
\text { limit }\end{array}$ & $\begin{array}{c}\text { Upper } \\
\text { limit }\end{array}$ \\
\cline { 2 - 4 } & 97.706 & 94.276 & 101.260 \\
\hline $\mathrm{C}_{\max }(\mathrm{ng} / \mathrm{ml})$ & 102.554 & 96.019 & 109.532 \\
\hline AUC $_{0-72}(\mathrm{ng} . \mathrm{hr} / \mathrm{ml})$ & &
\end{tabular}

Table 2: Data of 90 \% C.I for generic and reference cyclobenzaprine products.

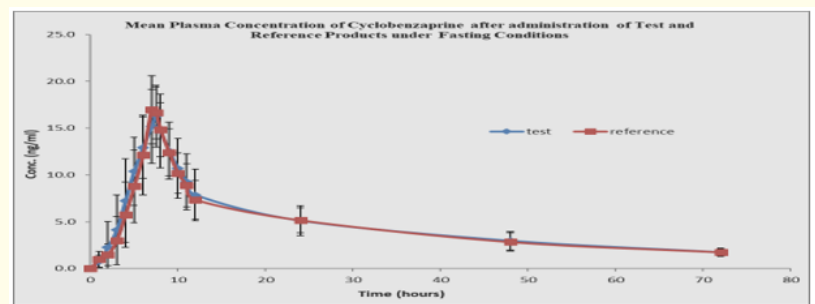

Figure 1: Plasma concentration (Mean $\pm \mathrm{SD}$ ) after dose administration of test (generic) and reference products of cyclobenzaprine $30 \mathrm{mg}$ sustained release capsule.
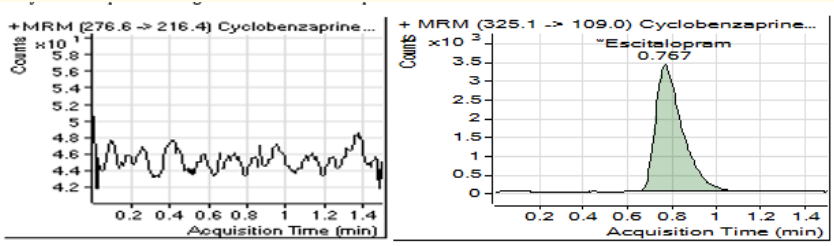

Figure 2: MRM of blank plasma spiked with escitalopram.
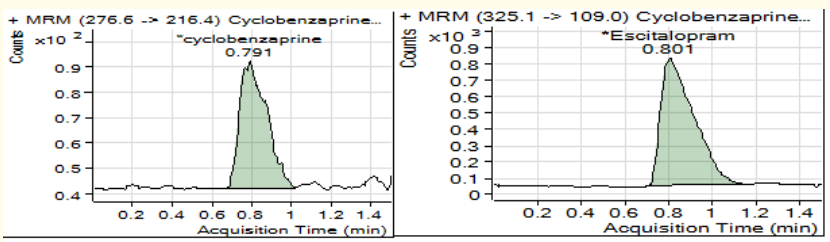

Figure 3: MRM of blank plasma spiked with $0.05 \mathrm{ng} / \mathrm{ml}$ Cyclobenzaprine and Escitalopram.
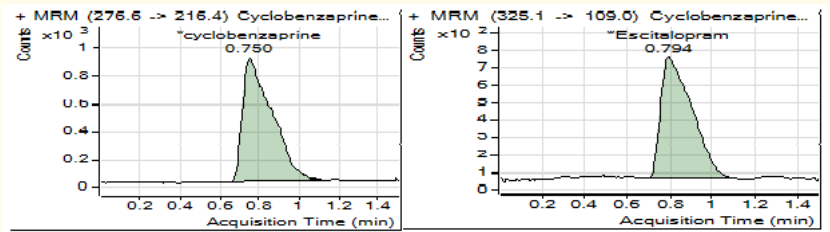

Figure 4: MRM of blank plasma spiked with $10 \mathrm{ng} / \mathrm{ml}$ cyclobenzaprine and escitalopram.

\section{Statistical analysis}

The results of 2-way ANOVA on $\mathrm{C}_{\max } \mathrm{T}_{\max }$ and $\mathrm{AUC}_{0-72}$ for cyclobenzaprine showed that there was no significant difference between generic and reference product. The point estimate (\%) results for $\mathrm{C}_{\max }$ and $\mathrm{AUC}_{0-72}$, were $97.706 \%$ and $102.554 \%$ respectively. The $90 \%$ C.I. of parametric means of $\mathrm{C}_{\max }$ and $\mathrm{AUC}_{0-72}$ were $94.276 \%$ to $101.260 \%$ and $96.019 \%$ to $109.532 \%$ respectively.

Citation: Nagwa A Sabri., et al. "Quantification of Cyclobenzaprine in Human Plasma by LC/MS/MS and its Pharmacokinetics Application". Acta Scientific Pharmaceutical Sciences 4.11 (2020): 90-96. 


\section{Discussion}

The developed validated bioanalytical LC/MS/MS method proved to be sensitivity, specific, precise and accurate and linear over the range of 0.05 to $50 \mathrm{ng} / \mathrm{ml}$ with $\mathrm{r}^{2}$ value of 0.9998 which is in accordance with FDA Guidelines [23] moreover, the developed bioanalytical method could be applied in different clinical applications, including: pharmacokinetics and bioavailability studies, clinical trials, and therapeutic monitoring of cyclobenzaprine to insure achievement of therapeutic goals.

The importance of therapeutic monitoring of cyclobenzaprine was being emerged from being structurally similar to tricyclic anti-depressants [1] that raise a concerns about potential adverse events which might occur during disease management. Additionally, therapeutic monitoring ensures that patients' drug levels are within the required therapeutic range and absence of subtherapeutic levels or toxic levels which increases the incidence of adverse events. Cyclobenzaprine is an adjuvant therapy that can be used with physiotherapy for relaxing muscle spasm in low back pain, neck pain and fibromyalgia [5-7].

A sensitive LC/MS/MS bioanalytical assay for cyclobenzaprine in human plasma was reported in which it was extracted by protein precipitation with acetonitrile, the multiple reaction monitoring was based on $\mathrm{m} / \mathrm{z} 276.3 \rightarrow 215.1$ with LLOQ was $0.05 \mathrm{ng} / \mathrm{ml}$ [25].

The developed in-house bioanalytical method provides a linear dynamic range more than those reported in the literature [17-21]. Besides, it is nearly in accordance with another published literature bioanalytical method [25] after modification in extraction and chromatographic conditions method. The used extraction method in our developed method was liquid-liquid extraction instead of protein precipitation in order to obtain a more purified plasma samples and thus more accurate determination. Moreover, the current study findings were nearly similar to those reported in the literature $[8,9]$.

In a bioequivalence study, the $90 \%$ C.I of $80 \%$ to $125 \%$ should be fulfilled on ln-transformed data of $\mathrm{AUC}_{0-72}$ and $\mathrm{C}_{\max }$. In the current study, the point estimate $(\%)$ results for $\mathrm{C}_{\max }$ and $\mathrm{AUC}_{0-72}$ were $97.706 \%$ and $102.554 \%$ respectively. The $90 \%$ C.I. of parametric means of $\mathrm{C}_{\text {max }}$, and $\mathrm{AUC}_{0-72}$ were $94.276 \%$ to $101.260 \%$, and $96.019 \%$ to $109.532 \%$ respectively indicating that $90 \%$ C.I. limits lied within the acceptance limits of $80 \%$ to $125 \%$ [24].

\section{Conclusion}

Monitoring of patient's drug levels is a critical step for achievement of a successful therapeutic treatment and avoidance of subtherapeutic or toxic drug levels. It could be concluded that the developed method for quantitation cyclobenzaprine in plasma is fully validated and cost-effective. The method could be used in bioavailability and bioequivalence studies, clinical trials, therapeutic monitoring, efficacy and safety studies. Moreover, statistical analysis of the mean values obtained in the bioequivalence study applied showed a non-significance difference of generic and reference products and therefore similar regarding rate and extent of absorption.

\section{Bibliography}

1. Alison Brayfield. "Martindale-The Complete Drug Reference" 38 ${ }^{\text {th }}$ edition, Pharmaceutical Press, London, UK (2014): 2023.

2. Katz WA., et al. "Cyclobenzaprine in the treatment of acute muscle spasms: review of a decade of clinical experience". Clinical Therapeutics 10 (1988): 216-228.

3. De Lee JC., et al. "Skeletal muscle spasm and a review of muscle relaxants". Current Therapeutic Research 27 (1980): 64-74.

4. Anonymous. "Extended-release cyclobenzaprine (Amrix)". The Medical Letter 49 (2007): 102-103.

5. Van Tulder MW., et al. "Muscle relaxants for non-specific low back pain". Cochrane Database of Systematic Reviews 4.2 (2003): CD004252.

6. Chou R., et al. "Comparative efficacy and safety of skeletal muscle relaxants for spasticity and musculoskeletal conditions: a systematic review". Journal of Pain and Symptom Management 28.2 (2004): 140-175.

7. Highlights of Prescribing Information, AMRIX ${ }^{\circledR}$ (cyclobenzaprine hydrochloride extended-release capsules), for oral use, approved by the U.S. Food and Drug Administration, AMRIFU-001 (2019).

8. $\quad$ AMRIX $^{\circledR}$ (Cyclobenzaprine Hydrochloride Extended-Release Capsules), N021777/S-012, AMR-005, (2013).

9. Darwish and Xie. Comparison of the Single-Dose Pharmacokinetics of Once-Daily Cyclobenzaprine Extended-Release 30 $\mathrm{mg}$ and Cyclobenzaprine Immediate-Release $10 \mathrm{mg}$ Three Times Daily in the Elderly". Drugs Aging 26.2 (2009): 95-101.

10. D Faber. Journal of Chromatography A 12 (1974): 675. 
11. H Hucker and S Stauffer. Journal of Chromatography A 124 (1976): 164.

12. M. Constanzer, et al. Journal of Chromatography A 339 (1985).

13. P Hwang., et al. Journal of Liquid Chromatography 16 (1993): 1163.

14. Constanzer M., et al. "Development and comparison of highperformance liquid chromatographic methods with tandem mass spectrometric and ultraviolet absorbance detection for the determination of cyclobenzaprine in human plasma and urine". Journal of Chromatography B 666 (1995): 117e126.

15. Darwish M., et al. "Single-dose pharmacokinetics of once-daily cyclobenzaprine extended release $30 \mathrm{mg}$ versus cyclobenzaprine immediate release $10 \mathrm{mg}$ three times daily in healthy young adults: a randomized, open-label, two period crossover, single-centre study". Clinical Drug Investigation 28 (2008): $793 \mathrm{e} 801$.

16. Brioschi TM., et al. "Pharmacokinetics and bioequivalence evaluation of cyclobenzaprine tablets". BioMed Research International (2013): 281392.

17. Hwang., et al. "Quantitative Determination of Cyclobenzaprine In Human Plasma By High Pressure Liquid Chromatography". Journal of Liquid Chromatography 16.5 (1993): 1163-1171.

18. Tatiane Maria de Lima Souza Brioschi., et al. "Pharmacokinetics and Bioequivalence Evaluation of Cyclobenzaprine Tablets". Bio Med Research International (2013).

19. M Constanzer., et al. "Development and comparison of highperformance liquid chromatographic methods with tandem mass spectrometric and ultraviolet absorbance detection for the determination of cyclobenzaprine in human plasma and urine". Journal of Chromatography B 666 (1995): 117-126.

20. Wenhong Yu., et al. "Rapid and sensitive analysis of cyclobenzaprine by LC/MS/MS: Application to a pharmacokinetic study of cyclobenzaprine in dog". Asian Journal of Pharmaceutical Sciences 9 (2014): 117-122.

21. Y Xiang., et al. "Determination of cyclobenzaprine in human plasma by liquid chromatography electrospray ionization tandem mass spectrometry and its application in a pharmacokinetic study". Biomedical Chromatography (2011).

22. CFR. Guidelines on the design of a single-dose in vivo bioavailability or bioequivalence study (2013).

23. Guidance for Industry Bioanalytical Method Validation (2018).
24. Guidance for Industry, Bioequivalence Studies with Pharmacokinetic Endpoints for Drugs Submitted Under an ANDA (2013).

25. Ronilson A Moreno., et al. "Comparative Bioavailability and Pharmacodynamic Aspects of Cyclobenzaprine and Caffeine in Healthy Subjects and the Effect on Drowsiness Intensity". Journal of Bioequivalence 1.3 (2009): 086-092.

\section{Assets from publication with us}

- Prompt Acknowledgement after receiving the article

- Thorough Double blinded peer review

- Rapid Publication

- Issue of Publication Certificate

- High visibility of your Published work

Website: www.actascientific.com/

Submit Article: www.actascientific.com/submission.php

Email us: editor@actascientific.com

Contact uS: +919182824667 